\title{
SOBRE LAS MATERIAS ARBITRABLES EN EL DERECHO ADMINISTRATIVO
}

\author{
Juan Pablo Aguilar Andrade
}

Se me ocurre que el origen de los problemas que enfrentamos al tratar sobre las materias arbitrables en el ámbito de Derecho Administrativo, proceden de dos enfoques distintos que, por unilaterales, acaban siendo caras opuestas de una misma medalla: de un lado, la creencia en que las instituciones del Derecho Privado no admiten más lógicas que las propias del Derecho Privado; del otro, la autonomía del Derecho Administrativo entendida como la creación de un espacio cerrado y autosuficiente, que no admite la intromisión de otras disciplinas jurídicas.

La diferencia de enfoques no impide llegar a resultados comunes, como se puede ver con claridad en el ámbito de la contratación administrativa. Así como desde las nociones clásicas de igualdad y autonomía de la voluntad, se niega la posibilidad de que existan contratos administrativos distintos de los de Derecho Privado, en el campo del Derecho Administrativo se desarrollaron teorías que consideraban la posibilidad de contratar como un inaceptable desconocimiento de que la administración actúa por medio de órdenes unilaterales, no de acuerdos de voluntad ${ }^{1}$.

En materia de arbitraje, si bien se ha generalizado su aceptación como instrumento para solucionar controversias en las que interviene la administración, muchos administrativistas no entienden sus particularidades y lo siguen viendo con recelo y,

1. Sobre las doctrinas del Derecho Administrativo que niegan la existencia de los contratos administrativos puede verse Héctor Jorge Escola, Tratado Integral de los Contratos Administrativos, Buenos Aires, Depalma, 1977, tomo I, pp. 34-40. 
desde el campo de los civilistas, se pretende aplicar a la administración el mismo aparato doctrinal que se utiliza en el arbitraje privado.

Esto último es menos una invasión deliberada, que la necesidad de cubrir los espacios abandonados por el Derecho Administrativo. En efecto, para este último el arbitraje sigue siendo una institución extraña, casi un intruso al que no queda más remedio que aceptar porque así es el tiempo que nos ha tocado vivir; los administrativistas, tan pronto como limitan el espacio que le asignan al arbitraje, abandonan el campo y lo dejan en manos del Derecho Privado, renunciando así a entender la institución desde el punto de vista de lo público.

Una buena muestra de ello es la forma en que se trata un concepto que en el Derecho Privado resulta fundamental a la hora de establecer qué materias pueden ser objeto de arbitraje: la transigibilidad.

\section{TRANSIGIBILIDAD}

Para que una materia pueda ser sometida a arbitraje es necesario que sea transigible, esto es, que verse sobre derechos de los que su titular pueda disponer libremente ${ }^{2}$. Esta exigencia, plenamente explicable en el ámbito del Derecho Civil, se ha trasladado sin más al Derecho Administrativo 3 a partir de la idea de que los conceptos de transigibilidad y de no transigibilidad, se relacionan con el de potestad reglada y el de potestad discrecional.

2. En el caso ecuatoriano, esta exigencia se establece en el articulo 4 de la Ley de Arbitraje y Mediación, Registro Oficial 417, 14 de diciembre de 2006: "Podrán someterse al arbitraje regulado en esta Ley las personas naturales o jurídicas que tengan capacidad para transigir ...". Hay legislaciones, sin embargo, para las que el criterio de arbitrabilidad se relaciona con el contenido patrimonial de la matcria.

3. Véase, por ejemplo, Juan Manuel Trayter, "Fl arbitraje de Derecho Admitistrativo", en Revista de Adminisuración Pública, Madrid, Centro de Estudios Constitucionales, número 143, mayo-agosto 1997, p. 95; Allan R. Brewer-Carias, Contratos administrativos, Caracas, Editorial Jurídica Venezolana, 1992, p. 268; Jorge Dussán Hitscherich, Elementos del contrato estatalal, Bogotá, Fundación Universidad de Bogotá Jơge Tàdeo Lozano, 2005, p. 208; Antonio J. Pérez y Efrain Pérez, Manual de contratos del Estado, Quito, Corporación de Estudios y Publicaciones, 2008, p. 326. 
Me referiré más adelante a esto último; por lo pronto me quedo con el concepto de transigibilidad, cuyo uso en el ámbito de la administración pública debe matizarse a partir del principio de legalidad, que establece una diferencia de fondo que debería ser tomada en cuenta: los órganos administrativos no son titulares de derechos, ejercen competencias.

En efecto, la administración no obra libremente sino que está sometida a la legalidad, actúa solo en la medida en que una norma les autoriza a hacerlo. La actividad administrativa no es ejercicio de libertad, sino "de un poder atribuido previamente por la Ley y por ella delimitado y construido" 4 ; en esa medida, no es un poder libre sino un poder sometido a la norma y, como tal, "obligado a dar cuenta de su efectivo servicio a la función para la que fue creado"s.

Mientras los particulares, en ejercicio de la autonomía que les es propia, pueden disponer libremente de sus derechos en la medida en que no exista prohibición expresa para ello ${ }^{6}$, los órganos administrativos no tienen intereses individuales, sino que actúan en consideración al interés de la comunidad.

Los rasgos que configuran los derechos subjetivos se distinguen de las notas características de las potestades de que están investidas las Administraciones Públicas ... El contenido de los derechos subjetivos se descompone en "facultades" ..., que como su propio nombre indica son de ejercicio voluntario o facultativo

A diferencia de los derechos subjetivos que son renunciables y transmisibles porque satisfacen intereses de su titular, las potestades son intransmisibles e irrenunciables porque están orientadas a satisfacer el interés ajeno (en el caso que aquí importa las potestades administrativas no satisfacen intereses particulares de la

4. Eduardo García de Enterria y Tomás-Ramón Femández, Curso de Derecho Administrative, Madtid, Civitas, 2001, tomo I, p. 441.

5. Tomás R. Fernández, De la arbitrariedad de la administración, Madrid, Civitas, 2002, p. 89.

6. El Código Civil ecuatoriano expresa esta regla en su artículo 11: "Podrán renunciarse los derechos conferidos por las leyes, con tal que sólo miren al interés individual del renunciante, y que no esté probibida su renuncia". 
propia Administración Pública, sino que tienen por finalidad satisfacer los intereses de los ciudadanos o intereses generales). Las potestades con un título fiduciario en beneficio de un tercero, y por ello son de obligado ejercicio. ${ }^{7}$

Siendo esto así, la capacidad de transigir y, con ella, la de pactar un arbitraje, es entre los privados la regla: todo es transigible, todo puede ser objeto de arbitraje, salvo prohibición expresa. En el caso de la administración ocurre exactamente lo contrario: la posibilidad de transigir o de pactar un arbitraje está supeditada necesariamente a la existencia de una expresa autorización legislativa.

El carácter convencional del arbitraje desaparece cuando se trata de órganos administrativos; es evidente que para estos últimos es también necesario un convenio arbitral, pero éste no se deriva de la mera voluntad del titular del órgano sino de la existencia de una habilitación legislativa.

En consecuencia, cuando se trata de la administración, lo arbitrable no tiene que ver con aquello de lo cual se pueda disponex libremente, con la transigibilidad, sino con la existencia de una potestad expresamente conferida por la ley.

\section{Discrecionalidad}

Las potestades discrecionales son el elemento que ha permitido dar sustento a la idea de transigibilidad en el Derecho Administrativo, a partir de identificar lo discrecional con lo disponible. Como vamos a ver, tampoco esto es exacto.

Hay consenso en admitir que el ejercicio de la potestad reglada no puede ser objeto de arbitraje, lo que resulta completamente lógico si se toma en cuenta que en ese caso la adminis-

7. David Blanquer, Curso de Derecho Administrativo, Valencia, Tirant lo Blanc, 2006, tomo II, p. 205. 
tración no hace otra cosa que cumplir un expreso mandato legal y que admitir la pretensión de transar sería tanto como dar a las leyes el carácter de negociables. Lo mismo puede decirse de los elementos reglados de la potestad discrecional ${ }^{8}$, como lo sostiene Juan Manuel Trayter:

... no podrá nunca versar el arbitraje sobre actos administrativos reglados o sobre ejercicio de potestades discrecionales ... en sus aspectos también reglados ... Como hemos ya señalado, una de las notas esenciales del arbitraje es que las cuestiones litigiosas por él resueltas deben ser «materias de libre disposición», circunstancia que no concurre en los supuestos señalados. ${ }^{9}$

¿Se puede considerar a la potestad discrecional como materia de libre disposición?

Aunque legislaciones como la ecuatoriana mantienen que no cabe el control judicial de actos administrativos emitidos en ejercicio de potestades discrecionale ${ }^{10}$, la doctrina más reciente apunta a superar este punto de vista y sostiene que no hay decisiones administrativas excluidas del control judicial. La polémica entre Tomás R. Fernández, por un lado, y Luciano Parejo Alfonso y Miguel Sánchez Morón, por otro, ha definido con claridad la necesidad de terminar con la inmunidad del ejercicio de las potestades discrecionales. No está demás decir que esta polémica, como hace notar Manuel Atienza, se basa en una diferencia "más de énfasis que propiamente teórica"11, pues los tres autores coinciden en la necesidad de controlar judicialmente la discrecionalidad.

8. La jurisprudencia ecuatoriana recoge de García de Enterria y Fernánđez el concepto de elementos reglados de la potestad discrecional y establece que éstos son, básicamente, la existencia misma de la potestad, su extensión, la competencia para ejercerla y la finalidad específica que se ha previsto para cada caso. Gaceta Judicial, serie XVII, número 9, p. 2966.

9. Juan Manuel Trayter, op.cit., p. 95.

10. Ley de la Jurisdicción Contencioso Administrativa, Registro Oficial 338, 18 de marzo de 1968, art. 6: “No corresponden a la jurisdicción contencioso - admíuistrativa: a) Las cuestiones que, por la naturaleza de los actos de los cuales procede o de la materia sobre que verse, se refieren a la potestad discrecional de la administración ..."

11. Manuel Atienza, Cuestiones judiciales, México, Fontamara, 2004, p. 53. 
Esto porque lo discrecional no puede entenderse, a riesgo de convertirse en arbitrariedad, como libertad del titular del órgano administrativo para hacer lo que le parezca. En efecto, la ley, cuando asigna potestades discrecionales, no da manos libres a la administración sino que le permite optar por el camino que considere más adecuado para satisfacer los intereses colectivos. Es esto último lo que debe justificarse $y$, para ello, resulta esencial la motivación. Lo no motivado, dice Fernández, se convierte en arbitrario ${ }^{12}$.

El poder administrativo en un Estado de Derecho es siempre, y más todavía el poder discrecional, un poder funcional, un poder obligado a dar cuenta de su efectivo servicio a la función para la que fue creado ... ${ }^{13}$

La decisión administrativa, entonces, no es una mera expresión de voluntad ni un simple querer del titular del órgano; solo se justifica si tiene como antecedente una evaluación detallada de razones y circunstancias, si se justifica como necesaria para el cumplimiento de los fines de orden público a los que se dirige.

La discrecionalidad, entonces, no implica capacidad para disponer libremente sobre el ejercicio de la potestad, sino la existencia de "cierto margen de apreciación" que permite analizar opciones pero que, en definitiva, debe concretarse en una decisión que se justifique como necesaria para el interés colectivo. Ese interés colectivo no es transable; en consecuencia, la decisión se justifica en función de fines de orden público y negociarla sería tanto como negociar esos fines.

Parece, entonces, que la supuesta identificación entre lo transigible y lo discrecional, no existe y, por ende, las declaraciones unilaterales de la administración no pueden considerarse como materia susceptible de someterse al arbitraje.

12. Tomás R. Fernández, op. cit, p. 87.

13. Tomás R. Fernández, op. cit., pp. 88-89. 


\section{CONVENCIONES}

Los órganos de la administración no actúan únicamente por medio de actos unilaterales, sino que llegan a acuerdos con otros órganos administrativos o con personas de derecho privado, utilizando para el efecto distintas figuras convencionales o contractuales.

Así como la declaración unilateral de voluntad es la institución jurídica central del Derecho Administrativo, la convención lo es del Derecho Privado, en la medida en que se convierte en el único medio para generar relaciones jurídicas entre personas libres e iguales. No han faltado autores que han sostenido que la administración solo puede obrar por medio de actos unilaterales y no puede recurrir a las convenciones ${ }^{14}$, pero en la actualidad es generalmente aceptada la idea de que la administración puede utilizar figuras propias del Derecho Privado, sin que ello afecte sus potestades ni cuestione los fundamentos del Derecho Administrativo.

En los países que han asumido como propia la cultura del régimen administrativo, el reconocimiento de que la Administración se somete a un derecho distinto al de los particulares, que gira alrededor de las prerrogativas de orden público, no ha impedido que "amplios sectores de la acción administrati$v a$ " puedan "ser abandonados al derecho común"15.

Cuando la Administración expresa su voluntad por medio de convenciones, utiliza un instrumento propio del Derecho Privado $y$, sobre todo, no se impone unilateralmente sino que fija de común acuerdo las condiciones de la relación ${ }^{16}$. Siendo

14. Según Otto Mayer, "el Estado sólo puede actuar unilateralmente, por medio de actos administrativos, y ... los actos de sumisión de los particulares, con su consentimiento, si bien se denominan contratos, or su estructura jurídica no son tales, usándose la designación de contratos de derecho público, sólo para distinguirlos de los contratos civiles, con los cuales guardan cierta similitud aparente", Héctor Jorge Escola, op.cit., p. 34.

15. Jean Rivero, Páginas de Derecho Administrativo, Bogotá, Temis - Universidad del Rosario, 2002, p. 190.

16. El hecho de que los contratos que celebra la Administración sean, por lo general, contratos de adhesión, no impide que los términos de la relación contractual se definan, no solo a partì de las reglas establecidas por el sector público, sino también conforme las condiciones planteadas en las ofertas presentadas por los contratistas. 
esto así, no hay razón para que los conflictos que puedan surgir de esta relación convencional no puedan solucionarse recurriendo a otro instrumento propio del Derecho Privado: el arbitraje.

El campo de las convenciones se convierte así, para usar las palabras de Juan Manuel Trayter, en "el hábitat natural donde va a desenvolverse con mayor soltura el arbitraje"17, precisamente porque se abre un espacio de negociación que permite a la Administración, por medio de instrumentos propios del Derecho Privado, convenir con los particulares las condiciones más adecuadas para el cumplimiento de los fines públicos.

Cuando contrata, la administración renuncia a la imposición unilateral de su voluntad y consigue sus objetivos en acuerdo con los particulares ${ }^{18} \mathrm{y}$, al hacerlo, genera relaciones de contenido patrimonial. La combinación del contenido patrimonial, la intervención de los particulares y la utilización de "la figura par excellence del Derecho Privado"19, el contrato, es lo que convierte al arbitraje en una posibilidad para solucionar controversias relacionadas con ese contenido patrimonial.

\section{Autotutela}

Jaime Vidal Perdomo califica al Derecho Administrativo como un derecho de frontera por los espacios que comparte con otras ramas jurídicas, espacios que generan áreas conflictivas como las que pueden encontrarse a lo largo de la extensa frontera con el Derecho Privado, que carece de la nitidez suficiente

17. Juan Manuel Trayter, op.cit., p. 95. La posibilidad de que las controversias contracmales de la Administración se resuelvan por medio del arbitraje se admite en varjos países, a partir de expresas autorizaciones legislativas. En el Ecuador, el artículo 4 de la Ley de Arbitraje y Mediación (Registro Oficial 4I7, 14 de diciembre de 2006) y el artículo 104 de la Ley del Sistema Nacional de Contratación Pública (Registro Oficial 395, 4 de agosto de 2008); cn Colombia, cl artículo 70 de la Ley 80 de 1993; en el Perú, el articulo 53 de la Ley de Contrataciones y Adquísiciones del Estado.

18. “... el Estado no está obligado a interyenir en todos los casos imponiendo su voluntad a los particulares. En algunas ocasiones puede obtener la colaboración voluntaria de éstos y lograr de ellos por medio de un arreglo consensual la prestación de bienes o servicios personales". El texto pertenece a Fraga, citado por Hector Jorge Escola, op. cit., p. 3 I.

19. Eduardo Garcia de Enterria y Tomás-Ramón Fernández, op. cit., tomo I, p. 672. 
como para establecer límites claros, especialmente en los terrenos ocupados por instituciones compartidas ${ }^{20}$.

Uno de esos terrenos es el de los actos convencionales, precisamente porque implican la utilización de una figura propia del Derecho Privado para los fines de la administración. Que esta última goza de prerrogativas para hacer prevalecer el interés general frente a los intereses del contratista, es algo generalmente aceptado; no es claro, sin embargo, hasta qué punto esas prerrogativas afectan las reglas propias de la contratación entre particulares. Este es un problema de particular importancia cuando se trata del arbitraje. Susana Montes de Echeverri, al analizar la posición que la jurisprudencia colombiana ha adoptado sobre la materia, comenta:

... es claro que la actuación de la Administración dentro de una relación contractual tiene una naturaleza distinta a aquella que cumple cuando actúa en función de imperio. En este caso, tiene un comportamiento similar al del particular dentro de la relación contractual, aun cuando tenga prerrogativas especiales. Así, según mi opinión, todas las manifestaciones de voluntad de la Administración en un contrato estatal pueden ser analizadas y juzgadas por el juez arbitral. ${ }^{21}$

No cabe duda que, al contratar, el comportamiento de la Administración es similar al de los particulares; esto, sin embargo, no hace que deje de ser Administración ni impide que las prerrogativas especiales que se le reconocen modifiquen o, para usar la expresión de García de Enterría y Fernández, modulen la institución contractual ${ }^{22}$.

La pretensión de que el contrato administrativo sea sustancialmente diferente al contrato de Derecho Privado, no puede sostenerse. Los llamados contratos administrativos son también

20. Jaìme Vidal Perdomo, DerecheAdministrativo, Bogotá, Legis, 2008, pp. 5 y 8 .

21. Susana Montes de Echeverri, "La solución de controversias contractuales por la via arbitral", en Revista de Derecho Páblico, Bogotá, Universidad de Los Andes, número 14, junio de 2002, p. 141.

22. Eduardo Garcia de Enterría y Tomás-Ramón Fernández, op, cit., tomo I, p. 681. 
contratos y su aplicación al ámbito del Derecho Administrativo no tiene por qué "comportar un régimen institucional radicalmente diferente $^{\prime 23}$. Pero eso no implica que la presencia de la Administración no introduzca en los contratos ciertas notas características que se derivan "de la posición jurídica general de la Administración de su privilegio general de autotutela" 24 .

La Administración, en la medida en que representa el interés colectivo, debe estar en capacidad para hacerlo prevalecer frente a los intereses particulares. El privilegio de autotutela le permite hacerlo, en la medida en que le capacita "como sujeto de derecho para tutelar por sí misma sus propias situaciones jurídicas, incluso sus pretensiones innovativas del statu quo, eximiéndose de este modo de la necesidad, común a los demás sujetos, de recabar una tutela judicial" ${ }^{\prime 25}$.

No hay razón para que la autotutela no se exprese en el ámbito de las declaraciones de voluntad común celebradas entre la Administración y los particulares. Ese es el origen de las cláusulas exorbitantes, que se consideran como característica propia de los contratos administrativos y que, pese a su nombre, no tienen origen contractual sino que derivan, precisamente, de las potestades generales de autotutela de la Administración.

Estas potestades se ejercen por medio de declaraciones unilaterales de voluntad. Ellas nos sacan, entonces, del campo de lo convencional, y nos devuelven al mundo de los actos de autoridad.

Parece claro, a partir de ésto, que la contratación administrativa suma, a los elementos propios de todo contrato, la posibilidad que la administración tiene de intervenir, en ejercicio de su autoridad, para la preservación del interés colectivo. Demás está decir que esta intervención es posible únicamente cuando haya una norma legal que la autorice.

23. Eduardo Garcia de Enterría y Tomás-Ramón Fernández, op. cit., tomo l, p. 680.

24. Eúuardo García de Enterría y Tomás-Ramón Fcrnández, op. cit., tomo 1, p. 683.

25. Eduardo García de Enterria y Tomás-Ramón Fernández, op. cit., tomo I, p. 505. 
La posibilidad de arbitraje, que hemos identificado para el caso de los actos convencionales, se limita según lo dicho a todo aquello que no tenga que ver con el ejercicio de potestades públicas que puedan afectar la ejecución contractual, potestades que son extracontractuales y que no tienen que ver con el acuerdo entre las partes, sino con el ejercicio del poder público.

La jurisprudencia del Consejo de Estado colombiano ha sido muy clara en relación con este punto:

... si bien es factible que las partes de un contrato -en donde una de ellas sea una entidad del Estado-, pueden convenir en someter a la decisión de árbitros las controversias que entre ellas surjan por situaciones de hecho derivadas del desarrollo o ejecución de dicho contrato, en modo alguno puede predicarse lo mismo respecto de la definición de la legalidad o ilegalidad de los actos administrativos que la entidad contratante expida con motivo de la celebración y ejecución del contrato, por cuanto las diferencias que el contratista pueda tener acerca del contenido y los efectos de este tipo de actos, no son, ni pueden ser, objeto de transacción y, por ende, tampoco de arbitramento, dado que en ello está comprometido el orden jurídico y el ejercicio del poder público, materias éstas que, en modo alguno, están sujetas a la disposición de las partes. ${ }^{26}$

Ésto debe entenderse en relación con los actos de la administración como tales, y no con sus consecuencias patrimoniales:

... la legalidad de los actos administrativos no es transigible $y$, por tanto, no puede someterse a decisión de los árbitros; pero por el contrario, las causas y los efectos patrimoniales de los actos administrativos podrán someterse a decisión del juez arbitral siempre y cuando la controversia no sea consecuencia directa de la legalidad del acto administrativo del cual se deriva y que los actos administrativos que sirvan de fundamento a la acción no

26. Consejo de Estado, Sección Tercera, 23 de febrero de 2000, caso Empresa de Transporte Masivo del Valle de Aburra, reproducida en Miguel González Radriguez, El contenciose centractual, Universidad Libre de Colombia, 2004, p. 317. 
hayan sido dictados en uso de los poderes excepcionales de la Administración. ${ }^{27}$

\section{Arbitrabilidad}

Para terminar, conviene volver a la idea de transigibilidad. Su utilización en el ámbito del Derecho Administrativo muestra que no puede aplicarse cuando se trata de declaraciones unilaterales de voluntad, ya sea que éstas se originen en el ejercicio de potestades regladas o de potestades discrecionales.

En el primer caso, los órganos administrativos se limitan a actuar conforme un expreso mandato legal que en ningún caso puede considerarse transigible. En el segundo, la opción escogida debe justificarse como necesaria para la satisfacción de intereses colectivos que, como tales, tampoco pueden ser negociables.

La posibilidad de arbitraje existe únicamente en los casos en que, acudiendo a instituciones propias del Derecho Privado, la administración fija, en acuerdo con los particulares, las reglas que regirán sus relaciones comunes. La base de la relación no es, en este caso, la orden unilateral de autoridad sino el convenio entre las partes; la transigibilidad está entonces presente y abre la puerta a la arbitrabilidad.

Esto, sin embargo, no deja de lado que la administración puede intervenir en los contratos que celebra para, en ejercicio de sus poderes de autotutela, proteger el interés público. En ese caso, sin embargo, nos encontramos frente a declaraciones unilaterales de voluntad que no tienen origen contractual $y$, en esa medida, no pueden ser sometidas a arbitraje.

Quito, mayo de 2008

27. Daniel Posse Velázquez, "Restricciones a las entidades estatales colombianas para acudir al arbitraje internacional", en Fernando Mantilla Serrano (coordinador), Anbitraje intemacional. Tensiones acluales Bogotá, Comité Colombiano de Arbitraje, Legis, 2007, p. 105. El autor, en este punto, resume el contenido de una sentencia del Consejo de Estado colombiano de 8 de junio de 2000 (exp. 16973). 